Somnologie (2016) 20: 47.

https://doi.org/10.1007/s11818-015-0034-4

\title{
Sleep equally benefits both emotional and neutral associative memories
}

\author{
Mick Lehmann ${ }^{1,2}$, Erich Seifritz ${ }^{1,2,3} \&$ Björn Rasch ${ }^{3,4}$,
}

1 Psychiatric University Hospital, Clinic of Affective Disorders and General

Psychiatry, Zurich, Switzerland

2 University of Zurich, Institute of Psychology, Zurich, Switzerland

3 Zurich Center for Interdisciplinary Sleep Research (ZiS), Zurich, Switzerland

4 University of Fribourg, Department of Psychology, Fribourg, Switzerland

ín

Corresponding author:

Björn Rasch, University of Fribourg, Department of Psychology, Division of Cognitive

Biopsychology and Methods, Rue P.-A.-Faucigny 2, CH-1701 Fribourg, Switzerland;

Email: Bjoern.Rasch@unifr.ch

Phone: +41263007637 


\begin{abstract}
Background

Emotions modulate memory. It has been suggested that sleep contributes to the improved memory for emotional events by preferentially consolidating emotional memories, presumably due to a selective off-line reactivation of information relevant for future behavior.

\section{Objectives}

We aimed at validating sleep-dependent memory consolidation in a new associative emotional memory paradigm suitable for inducing memory reactivations during sleep. We hypothesized that sleep preferentially benefits consolidation of emotional associations independently of their negative vs. positive emotional valence.

\title{
Methods
}

Seventy-two healthy young participants performed on an associative emotional memory task either in the evening or in the morning. During the task, they were asked to associate neutral spoken words to neutral, negative or positive pictures. Cued recall was tested after a $12-\mathrm{hr}$ retention interval filled with either nighttime sleep or daytime wakefulness.

\section{Results}

Generally, emotional associations were better remembered than neutral ones. However, we were not able to replicate a selective benefit of sleep on emotional memory. Sleep robustly improved cued recall performance of all pictures types as compared to wakefulness, without any modulating influence of emotional arousal or valence.

\section{Conclusions}

We conclude that consolidation of explicitly learned associations benefits from sleep independent of emotional arousal or valence. Selective emotional memory consolidation during sleep might be restricted to non-associative item memory or incidentally learned emotional associations.

Keywords: sleep, emotional memory, arousal, valence, emotional reactivity 


\section{Abstrakt}

\section{Hintergrund}

Emotionen beeinflussen die Gedächtnisbildung. Es wird angenommen, dass die

Gedächtniskonsolidierung im Schlaf zu diesem Effekt beiträgt und im Schlaf insbesondere emotionale Erinnerungen gefestigt werden. Dies geschieht möglicherweise über eine selektive Reaktivierung von zukunftsrelevanten Informationen.

\section{Ziel der Arbeit}

Das Ziel der Studie ist es, die schlaf-abhängige Gedächtniskonsolidierung eines neuen emotionalen Assoziationsparadigma zu validieren. Das Lernparadigma wäre zukünftig für die experimentelle Reaktivierung emotionaler Assoziationen im Schlaf geeignet. Die Hypothese lautet, dass sowohl negative als auch positive emotionale Assoziationen während des Schlafs bevorzugt gefestigt werden im Vergleich zu neutralen Assoziationen.

\section{Material und Methoden}

72 gesunde Versuchspersonen durchliefen entweder am Abend oder am Morgen eine assoziativ-emotionale Gedächtnisaufgabe. Dabei mussten neutrale gesprochene Wörter mit negativen, positiven oder neutralen Bildern assoziiert werden. Der Abruf wurde nach einer 12-stündigen Zeitspanne getestet, in der die Versuchspersonen entweder nachts schliefen oder tagsüber wach bleiben mussten.

\section{Ergebnisse}

Emotionale Assoziationen konnten allgemein besser erinnert werden als neutrale. Wir konnten jedoch nicht die selektive Verstärkung emotionaler Inhalte im Schlaf replizieren. Die Schlafgruppe zeigte insgesamt eine bessere Erinnerungsleistung als die Wachgruppe, unabhängig von der emotionalen Erregung und Valenz der gelernten Assoziationen.

\section{Diskussion}

Unsere Ergebnisse zeigen, dass im Schlaf explizit gelernte Assoziationen unabhängig von Faktoren wie emotionaler Erregung oder Valenz gefestigt werden. Die präferentielle Konsolidierung von emotionalen Inhalten im Schlaf scheint möglicherweise nur auf nichtassoziative Gedächtnisinhalte und inzidentell gelernte Assoziationen beschränkt zu sein. 
Lehmann, Seifritz \& Rasch

Schlüsselworte: Schlaf, emotionales Gedächtnis, Arousal, Valenz, emotionale Reaktivität 


\section{Introduction}

Emotional events are highly relevant for adaptive future behavior and therefore better remembered than neutral ones [15]. According to the widely accepted memory modulation hypothesis [21], consolidation of memories after encoding is strongly influenced by noradrenergic activation of the amygdala, which increases plastic processes in memoryrelated brain regions including the hippocampus. In support of this notion, numerous studies have demonstrated that emotions evoked by the learning material critically modulate memory consolidation (see [14], for a review). Furthermore, the memory advantage of emotional over neutral memories has been reported to increase with longer retention intervals between encoding and retrieval (e.g. $[12,13])$, suggesting a continuing influence of emotions on ongoing consolidation processes. While most studies have examined the influence of negative emotional memories ( see [14], for a review), some studies report similar or even increased memory benefits for stimuli associated with positive emotions $[1,20]$.

In addition to emotions, sleep has also been critically implicated in the consolidation of memories. Sleep benefits memory consolidation, presumably due to a spontaneous reactivation of newly encoded memories during subsequent Non-rapid-eye movement (NREM) sleep (see [28], for a review). According to the active system consolidation hypothesis [5], hippocampal memory reactivations during NREM sleep support the strengthening and integration of memories into cortical long-term stores. Furthermore, several authors have suggested that this consolidation process during sleep is selective, thereby specifically strengthening those memories that are relevant for our future behavior $[6,35]$. Supporting this concept, reward memories are preferentially reactivated during NREM sleep in rodents $[7,6]$ and sleep selectively strengthens memories associated with reward or future relevance in humans $[15,3,9]$. Also for emotional memories, several studies have reported a selective effect of sleep (see [25], for a review). For example, sleep or naps preferentially consolidate memories for negative pictures or stories as compared to neutral stimuli (e.g., [8, $11-13,22,26,32]$ and this effect is detectable even after several years [33]. In addition, sleep 
also selectively improves memory for neutral stimuli incidentally associated with a negative emotional context [27], while only one study so far provided evidence for a selective effect of sleep for positive emotions (i.e., humorous cartoons, [3]).

Here we aimed at validating sleep-dependent memory consolidation in a new emotional associative memory paradigm, which is potentially capable of reactivating emotional vs. neutral memories during sleep by verbal cueing in future studies. In addition, we directly compared the selective benefit of sleep on memory for positive vs. negative emotional pictures. In the associative emotional memory paradigm, participants are instructed to learn associations between neutral, spoken words and pictures presented visually on the screen. In the negative picture group, negative and neutral pictures are used, whereas participants in the positive picture group view positive and neutral pictures. We hypothesized that sleep (as compared to wakefulness) preferentially benefits consolidation of associations between words and emotional vs. neutral pictures, independently of their emotional valence. Furthermore, we tested the effect of sleep on changes on subjective arousal ratings for the initially neutral words. 


\section{Materials and Methods}

\section{Subjects}

A total of 76 healthy, right-handed subjects ( 16 men, age $22.1 \pm 0.7$ years, mean \pm standard error of the mean, SEM) participated in this study. Four participants had to be excluded from the final data analysis as they reached only very low memory performance levels (less than 15 correctly recalled associations out of 100 word-picture pairs immediately after learning), resulting in a final sample of 72 (14 men, mean age $22.0 \pm 0.3$ years, for details see Table 1). Subjects were advised not to sleep or to drink coffee during the day of testing as well as to refrain from drinking alcohol before going to sleep. Using a selfevaluation questionnaire, participants reported that they were not taking any medication at the time of the experiment nor had a history of any neurological or psychiatric disorder. All subjects reported a normal sleep-wake cycle and were not or pursuing shift work for at least 8 weeks before the experiments. The study was approved by the ethics committee of the Department of Psychology, University of Zurich, and all subjects gave written informed consent prior to participating. After completing the whole experiment, participants received a compensation of 36 Swiss francs (CHF). We performed a power analysis to determine the sample size controlling for an error probability of 0.05 and false negative rate of 0.1 (power of 0.9 ). In order to detect an emotion effect on memory consolidation over sleep of eta $^{2}=0.1$, as observed in Payne et al. (2008), a sample size of $n=44$ is required.

\section{Experimental design and General Procedure}

Participants were randomly assigned to a 'sleep group' or a 'wake group'. The 'sleep group' underwent the learning phase in the evening ( 9 p.m.) and recall performance was testes 12 hours later in the morning. Vice versa, the 'wake group' learnt in the morning (9 a.m.) and the retrieval phase followed 12 hours later in the evening. The groups were further divided in a 'negative pictures group' and a 'positive pictures group': The 'negative pictures' 
sleep and wake groups learned associations between neutral words and negative as well as neutral pictures. The 'positive pictures' sleep and wake groups learnt associations between neutral words and positive as well as neutral pictures. (Figure 1, for a summary of the procedure; for details on the demographic parameters of the four experimental groups see Table 1)

The first session started with subjective ratings of emotional arousal for single words and pictures separately (15-20 min). Afterwards, participants performed on the associative emotional memory task and encoded the word-picture pairs (30-35 min). After a delay of approximately 15 min during which participants filled out questionnaires, immediate memory retrieval was tested (baseline). Delayed retrieval was then tested after a retention interval of 12 hours either during day or night, respectively. Finally, participants rated again the arousal of all words without picture presentation.

\section{The associative emotional memory task}

The associative emotional memory task consisted of 100 words and pictures, which were grouped into association pairs. The words were two syllable substantives selected from the Berlin Affective Word List (BAWL-R, 2009), a German database providing normative ratings for emotional valence and arousal. The selection criterion was neutral rating with a very small standard deviation (mean rating $0 \pm 0.2 \mathrm{SD}$ on a -3 to +3 scale). In order to provide an auditory presentation, words were read by an actress and recorded in-house. The set of visual stimuli consisted of 150 pictures taken from the Nencki Affective Picture System (NAPS, [19]). 50 of these pictures are generally rated as neutral and low arousing. The remaining 100 pictures elicit a high level of emotional arousal, of which 50 pictures are perceived as positive and 50 as negative in emotional valence. The learning material for a single subject consisted therefore of 100 neutral words of which 50 words were associated with high arousing pictures and the other half was associated with low arousing pictures. The associations between words and pictures were balanced across participants. The emotional valence of the high arousing pictures was consistent for every participant and was either 
negative or positive. Participants of the study rated emotional pictures as more arousing than neutral pictures $\left(4.52 \pm 0.13\right.$ vs. $\left.2.46 \pm 0.10, t_{71}=13.60, P<0.001\right)$. In addition, negative pictures were perceived as significantly more arousing than the positive pictures $(5.01 \pm 0.14$ vs. $\left.4.03 \pm 0.2 ; t_{71}=16.22, P<0.001\right)$.

\section{Arousal ratings}

Prior to the associative emotional memory task, participants rated words and pictures separately on a 7-point Likert-scale with respect to the level of arousal, ranging from 'not at all arousing' to 'highly arousing'. Following a fixating cross displayed for $1000 \mathrm{~ms}$ in the center of the screen, the word was presented auditory via head phones. Subsequently, the rating scale was displayed and subjects were instructed to use the keyboard to indicate the arousal elicited by the stimulus. The rating of the picture followed the same procedure during which pictures were presented visually on the screen for $1500 \mathrm{~ms}$.

\section{The learning phase}

During the associative emotional learning paradigm, participants were instructed to memorize the word-picture pairs. They had to complete a total of three rounds: During the first round, the words were presented auditory after a fixation cross (1000 ms), followed by visual presentation of the picture on the computer screen. $1000 \mathrm{~ms}$ after picture onset, the word was played again. The picture was presented for $2500 \mathrm{~ms}$ followed by an inter-stimulus interval (ISI) with a random duration (1000-2000 ms). No response was required during the first learning round. During the subsequent two rounds, the first word presentation was followed by 7-point Likert-scale on which participants had to indicate whether they expected a low or high arousing picture. Subjects were instructed to press'7' (or ' 1 '), if they expected a high (or low, respectively) arousing picture after the word with highest certainty. The button ' 4 ' indicated no expectancy, the remaining button were used for different levels of confidence. Participants were instructed to avoid guessing and rely on their feelings of 
expectancy rather than on explicit memory for the picture. Finally, the picture was presented for $2500 \mathrm{~ms}$. Followed by an ISI between 1000 and $2000 \mathrm{~ms}$.

\section{The retrieval phase}

Retrieval performance was tested using a cued recall procedure: Each trial started with a fixation cross signalizing the auditory presentation of the word. If participants could remember the associated picture they had to press ' $\mathrm{Y}$ ' and subsequently type a short description of the content of the picture. If they did not remembered the associated pictures, they pressed ' $\mathrm{N}$ ' and the next word was presented. Retrieval performance was tested twice: $15 \mathrm{~min}$ after the three learning rounds (baseline) and after the 12-hr retention interval (final retrieval). As retention score we calculated the percentage of final retrieval performance with retrieval performance at baseline set to $100 \%$.

\section{Statistical analysis}

Data were analyzed using repeated analyses of variance (ANOVA) including the within-subject factor 'emotional arousal' (high vs. low arousing) and the between-subject factors 'sleep/wake' and 'group' (negative pictures group vs. positive pictures group). Posthoc pair-wise comparisons were conducted using $t$-tests. A probability of $P=0.05$ was set as significance threshold.

\section{Results}

\section{Memory performance at baseline}

Consistent with previous studies, during the learning phase we observed a strong advantage of recalling emotional as compared to neutral pictures (emotional memory effect (mean \pm SEM): $31.28 \pm 1.10$ vs. $28.90 \pm 1.12$ correctly recalled pictures, $t_{71}=4.65, P<$ $0.001, d=0.36$, see Table 2). The effect was observed both for negative vs. neutral pictures $(P<0.05)$ and positive vs. neutral pictures $(P<0.001)$, although the effect was larger for positive pictures in our study (significant interaction between the within-subject factor 
emotional arousal (high vs. low arousing) and the factor 'group' (negative vs. positive picture groups), $F_{(1,68)}=6.19, P=0.04$, eta $\left.{ }^{2}=0.06\right)$. Importantly, cued recall of word-picture pairs at baseline before the retention interval did not differ between sleep and wake groups (30.75 \pm 1.46 vs. $29.43 \pm 1.61$ pictures, $t_{71}=0.53, P=0.60$ ), rendering circadian confounds rather unlikely. Descriptively, participants in the 'negative pictures group' generally recalled fewer pictures as compared to the 'positive pictures group', although this effect did not reach statistical significance $\left(56.42 \pm 3.21\right.$ vs. $63.5 \pm 2.87$ pictures, $\left.t_{71}=-1.63, P=0.104, \mathrm{~d}=0.39\right)$. No further interactions were observed (all $P>0.70$ ).

\section{Sleep benefits memory consolidation of word-picture pairs}

Consistent with a beneficial role of sleep for memory consolidation, participants who slept after learning exhibited a significantly improved cued recall performance after the 12-hr retention interval as compared to participants who stayed awake after learning: Participants in the sleep groups remembered $99.07 \pm 1.80 \%$ of the learned word-picture pairs (with learning performance before sleep set to $100 \%$ ), whereas participants in the wake groups recalled only $90.19 \pm 1.96 \%\left(F_{(1,68)}=11.17, P<0.001\right.$ eta $^{2}=0.14$, see Table 3$)$. However in contrast to the notion of a selective effect of sleep on emotional memory consolidation, both emotional and neutral word-picture associations profited equally from a retention interval filled with sleep: While cued recall for emotional pictures was improved by ca. $9 \%$ after sleep as compared to the wake group $\left(98.01 \pm 2.23 \%\right.$ vs. $89.06 \pm 2.42 \%$, respectively, $t_{70}=2.75, P=0.008, \mathrm{~d}=$ 0.65), we observed a comparable improvement of ca. $9 \%$ for neutral pictures $(100.13 \pm 2.03 \%$ vs. $91.32 \pm 2.20 \%$, for sleep and wake groups, respectively $t_{70}=2.99, P=0.004, \mathrm{~d}=0.75$ ). Consequently, we observed no significant interaction between the factor sleep/wake and the within-subject factor emotional arousal (high vs. low arousing pictures; $F_{(1,68)}=0.002, P=$ 0.97). Similarly, we observed no significant interaction with the between-subject factor 'group' (negative vs. positive pictures group, $F_{(1,68)}=0.682, P=0.41$ ). Interestingly, memory consolidation of associations between words and emotional pictures did generally not differ from consolidation of neutral word-picture associations (main effect of emotional arousal: 
$93.54 \pm 1.65 \%$ vs. $95.73 \pm 1.50 \%$, respectively, $F_{(1,68)}=1.70, P=0.197$, eta $\left.^{2}=0.024\right)$. Our findings indicate that sleep strongly and robustly benefits cued recall of word-picture associations regardless of the emotional arousal and valence of the pictures.

\section{Sleep does not affect generalized emotional arousal of words}

Before the emotional association task, arousal ratings of neutral words that were later associated with emotional pictures did not differ from those words that were later associated with neutral pictures (on a 7-point scale: $2.68 \pm 0.12$ vs. $2.71 \pm 0.11, t_{71}=-0.57, P=0.57$, higher numbers indicate higher subjective arousal ratings). This was true for all four groups (see Table 2, for descriptive values). After the whole procedure (including the associative emotional memory task, the retention interval and the final retrieval test), words associated with emotional pictures were rated as more arousing as compared to words paired with neutral pictures $\left(134.91 \pm 6.68 \%\right.$ vs. $99.98 \pm 4.34 \%$; $\left.t_{71}=4.03, P<0.001, \mathrm{~d}=0.71\right)$ with arousal rating at baseline set to $100 \%$ ). The effect was stronger for those words associated with negative as compared to positive pictures $\left(F_{(1,70)}=4.58, P<0.04\right.$, see Table 3$)$, which fits well with our result that participants perceived negative pictures as more arousing. This result indicates that participants successfully associated words with the emotional vs. neutral pictures, and that the arousal effects generalized to arousal ratings of the word alone (without picture presentation). However, changes in arousal ratings of words associated with emotionally arousing pictures did not significantly differ between sleep and wake groups $\left(125.01 \pm 9.05 \%\right.$ vs. $144.80 \pm 9.84 \% ; F_{(1,68)}=2.39, P=0.127$, see Table 3$)$.

\section{Discussion}

Our results indicate that recall of word-picture associations profit strongly from retention periods filled with sleep. Thus, we successfully validated sleep-dependent memory consolidation in our associative emotional memory paradigm. In addition, emotion modulated memory in this task, as cued recall for emotional pictures (negative and positive) was 
generally increased as compared to neutral pictures. However, we were not able to replicate a selective benefit of sleep on emotional as compared to neutral associations. Sleep generally improved cued recall performance of word-picture pairs, independent of the emotional arousal and valence of the to-be-associated pictures. The latter finding contradicts previous studies reporting a preferential consolidation of emotional memories during sleep $[11,25]$. Most of these studies used either single-item memory of pictures [12, 13, 22] or emotional modulation by incidentally learned emotional contexts (i.e., background image, stories etc., $[26,27,32])$. In our study, participants were explicitly told to learn associations between neutral words and emotional as well as neutral pictures. Furthermore, participants were informed that these associations would be tested after sleep. Thus in our paradigm, also associations with neutral pictures are relevant for future behavior, and it might be possible that such a tagging with future relevance overrides selective consolidation of sleep for emotional memories. In a recent study, Groch and colleagues [10] tried to disentangle the effects of future relevance and emotional memory on sleep-dependent memory consolidation. They reported that while consolidation of emotional memories depends on REM sleep, memories with future relevance are mainly consolidated during NREM sleep. As we did not record polysomnography in our study, future studies need to examine possible shifts in sleepstage dependencies for consolidation processes related to the associative emotional memory task.

A further limitation of our study is that we did not control for possible differences in circadian time of the learning and retrieval phases between our sleep and wake groups. However, immediate recall performance did not significantly differ between the two groups, suggesting that encoding success is comparable for participants performing on the task either in the morning or in the evening. Similarly, arousal ratings of pictures did not depend on circadian time. Although it cannot be assumed that circadian time has in general no effect on memory processes, we consider a confounding influence in this study on arousal ratings and cued recall performance rather unlikely. 
As expected for the associative memory task, arousal ratings for words associated with emotional pictures increased during the course of learning. However, the change in arousal ratings after the 12-hr retention interval did not significantly differ between the 'sleep' and 'wake' group. A recent model proposed that sleep does not only strengthens the content of emotional memories but also reduces its associated affective tone [34]. Evidence for this model is quite inconsistent, as studies have reported a role of sleep in depotentiation $[4,24]$, but also a protection $[2,9]$, or even potentiation $[18,31]$ of emotional reactivity to arousing stimuli. Our findings add to this literature by showing that changes in generalized arousal ratings after learning of emotional associations are not differentially affected by sleep or wakefulness after learning.

To conclude, our results indicate that the consolidation of word-picture pairs in the associative emotional memory task profits from retention intervals filled with sleep. Thus, the task is suitable for examining potential mechanisms underlying processes of memory consolidation during sleep. In particular, the task can be used to induce reactivation of emotional vs. neutral memory association by verbal cueing during sleep. However, future studies are necessary to directly compare possible moderators of the selectivity of sleep for consolidating memories with a high future relevance.

\section{Acknowledgements}

We thank Donata Schmid,Laura Jagoda and Arndt Schaefer for their help in data collection.

\section{Funding}

This work was supported by a grant from the Swiss National Foundation (SNF) (PP00P1_133685) and the Clinical Research Priority Program "Sleep and Health" of the University of Zurich. 
Lehmann, Seifritz \& Rasch

\section{Conflict of interest}

None declared. 


\section{References}

1. Ackermann S, Hartmann F, Papassotiropoulos A et al (2015) No associations between interindividual differences in sleep parameters and episodic memory consolidation. Sleep 38:951—959. doi: 10.5665/sleep.4748

2. Baran B, Pace-Schott EF, Ericson C, Spencer RMC (2012) Processing of emotional reactivity and emotional memory over sleep. J Neurosci 32:1035-42. doi: 10.1523/JNEUROSCI.2532-11.2012

3. Chambers AM, Payne JD (2014) Laugh yourself to sleep: Memory consolidation for humorous information. Exp Brain Res 232:1415-1427. doi: 10.1007/s00221-013$3779-7$

4. Cunningham TJ, Crowell CR, Alger SE et al (2014) Psychophysiological arousal at encoding leads to reduced reactivity but enhanced emotional memory following sleep. Neurobiol Learn Mem 114:155-164. doi: 10.1016/j.nlm.2014.06.002

5. Diekelmann S, Born J (2010) The memory function of sleep. Nat Rev Neurosci 11:114-26. doi: 10.1038/nrn2762

6. Diekelmann S, Wilhelm I, Born J (2009) The whats and whens of sleep-dependent memory consolidation. Sleep Med Rev 13:309-21. doi: 10.1016/j.smrv.2008.08.002

7. Fischer S, Born J (2009) Anticipated reward enhances offline learning during sleep. J Exp Psychol Learn Mem Cogn 35:1586-1593. doi: 10.1037/a0017256

8. Groch S, Wilhelm I, Diekelmann S et al (2011) Contribution of norepinephrine to emotional memory consolidation during sleep. Psychoneuroendocrinology 36:13421350. doi: 10.1016/j.psyneuen.2011.03.006

9. Groch S, Wilhelm I, Diekelmann S, Born J (2013) The role of REM sleep in the processing of emotional memories: evidence from behavior and event-related potentials. Neurobiol Learn Mem 99:1-9. doi: 10.1016/j.nlm.2012.10.006

10. Groch S, Zinke K, Wilhelm I, Born J (2014) Dissociating the contributions of slowwave sleep and rapid eye movement sleep to emotional item and source memory. Neurobiol Learn Mem 122:122-130. doi: 10.1016/j.nlm.2014.08.013

11. Holland P, Lewis PA (2007) Emotional memory: Selective enhancement by sleep. Curr Biol 17:179-181. doi: 10.1016/j.cub.2006.12.033

12. Hu P, Stylos-Allan M, Walker MP (2006) Sleep facilitates consolidation of emotional declarative memory. Psychol Sci 17:891-898. doi: 10.1111/j.1467-9280.2006.01799.x

13. Kaestner E, Wixted J, Mednick S (2013) Pharmacologically Increasing Sleep Spindles Enhances Recognition for Negative and High-arousal Memories. 1-14. doi: $10.1162 /$ jocn

14. Kensinger E a. (2009) Remembering the details: Effects of emotion. Emot Rev 1:99113. doi: $10.1177 / 1754073908100432$ 
15. LaBar KS, Cabeza R (2006) Cognitive neuroscience of emotional memory. Nat Rev Neurosci 7:54-64. doi: 10.1038/nrn1825

16. Lansink CS, Goltstein PM, Lankelma J V et al (2008) Preferential reactivation of motivationally relevant information in the ventral striatum. J Neurosci 28:6372-6382. doi: 10.1523/JNEUROSCI.1054-08.2008

17. Lansink CS, Goltstein PM, Lankelma J V. et al (2009) Hippocampus leads ventral striatum in replay of place-reward information. PLoS Biol. doi: 10.1371/journal.pbio.1000173

18. Lara-Carrasco J, Nielsen T a., Solomonova E et al (2009) Overnight emotional adaptation to negative stimuli is altered by REM sleep deprivation and is correlated with intervening dream emotions. J Sleep Res 18:178-187. doi: 10.1111/j.13652869.2008.00709.x

19. Marchewka A, Zurawski L, Jednoróg K, Grabowska A (2014) The Nencki Affective Picture System (NAPS): Introduction to a novel, standardized, wide-range, highquality, realistic picture database. Behav Res Methods 46:596-610. doi: 10.3758/s13428-013-0379-1

20. Martínez-Galindo JG, Cansino S (2015) Positive and negative emotional contexts unevenly predict episodic memory. Behav Brain Res 291:89-102. doi: 10.1016/j.bbr.2015.05.018

21. McGaugh JL (2004) The amygdala modulates the consolidation of memories of emotionally arousing experiences. Annu Rev Neurosci 27:1-28. doi: 10.1146/annurev.neuro.27.070203.144157

22. Nishida M, Pearsall J, Buckner RL, Walker MP (2009) REM sleep, prefrontal theta, and the consolidation of human emotional memory. Cereb Cortex 19:1158-66. doi: $10.1093 /$ cercor/bhn 155

23. Oudiette D, Antony JW, Creery JD, Paller K a (2013) The role of memory reactivation during wakefulness and sleep in determining which memories endure. J Neurosci 33:6672-6678. doi: 10.1523/JNEUROSCI.5497-12.2013.The

24. Pace-Schott EF, Shepherd E, Spencer RMC et al (2011) Napping promotes intersession habituation to emotional stimuli. Neurobiol Learn Mem 95:24-36. doi: 10.1016/j.nlm.2010.10.006

25. Payne JD, Kensinger E a. (2010) Sleep's role in the consolidation of emotional episodic memories. Curr Dir Psychol Sci 19:290-295. doi: $10.1177 / 0963721410383978$

26. Payne JD, Kensinger EA, Wamsley EJ et al (2015) Napping and the selective consolidation of negative aspects of scenes. 15:1-11.

27. Payne JD, Stickgold R, Swanberg K, Kensinger E a. (2008) Sleep preferentially enhances memory for emotional components of scenes. Psychol Sci 19:781-788. doi: $10.1111 /$ j.1467-9280.2008.02157.x 
28. Rasch B, Born J (2013) About sleep's role in memory. Physiol Rev 93:681-766. doi: 10.1152/physrev.00032.2012

29. Sharot T, Verfaelli M, Yonelinas AP (2007) How emotion strengthens the recollective experience: A time-dependent hippocampal process. PLoS One. doi: 10.1371/journal.pone. 0001068

30. Sharot T, Yonelinas AP (2008) Differential time-dependent effects of emotion on recollective experience and memory for contextual information. Cognition 106:538547. doi: 10.1016/j.cognition.2007.03.002

31. Wagner U, Fischer S, Born J (2002) Changes in emotional responses to aversive pictures across periods rich in slow-wave sleep versus rapid eye movement sleep. Psychosom Med 64:627-634. doi: 10.1097/01.PSY.0000021940.35402.51

32. Wagner U, Gais S, Born J (2001) Emotional memory formation is enhanced across sleep intervals with high amounts of rapid eye movement sleep. Learn Mem 8:112-9. doi: $10.1101 / \mathrm{lm} .36801$

33. Wagner U, Hallschmid M, Rasch B, Born J (2006) Brief sleep after learning keeps emotional memories alive for years. Biol Psychiatry 60:788-90. doi: 10.1016/j.biopsych.2006.03.061

34. Walker MP, van der Helm E (2009) Overnight therapy? The role of sleep in emotional brain processing. Psychol Bull 135:731-48. doi: 10.1037/a0016570

35. Walker MP, Stickgold R (2010) Overnight alchemy: sleep-dependent memory evolution. Nat Rev Neurosci 11:218; author reply 218. doi: 10.1038/nrn2762-c1

36. Wilhelm I, Diekelmann S, Molzow I et al (2011) Sleep selectively enhances memory expected to be of future relevance. J Neurosci 31:1563-1569. doi: 10.1523/JNEUROSCI.3575-10.2011 
Figure 1

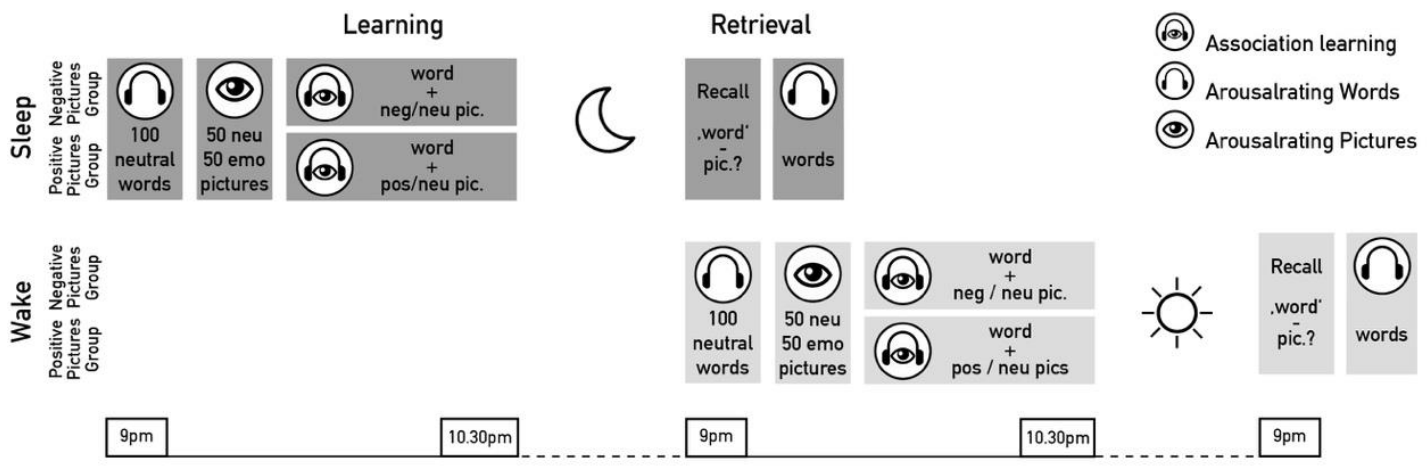

Experimental procedure. During learning, participants associated 100 neutral words with 50 emotionally high arousing (emotional, 'emo') and 50 low arousing pictures (neutral, 'neu'), respectively. Participants in the 'negative pictures group' associated words with negative ('neg') and neutral pictures, whereas participants in the 'positive pictures group' associated positive ('pos') and neutral pictures. Encoding success was tested immediately afterwards using a cued recall procedure, in which participants heard the word and had to provide a brief written description of the picture. Retrieval performance was assessed after a $12 \mathrm{hr}$-retention interval of filled with either sleep or wakefulness using the same cued recall procedure. The arousal of words and pictures was rated before the learning phase and for words again after the final retrieval phase. 
Figure 2
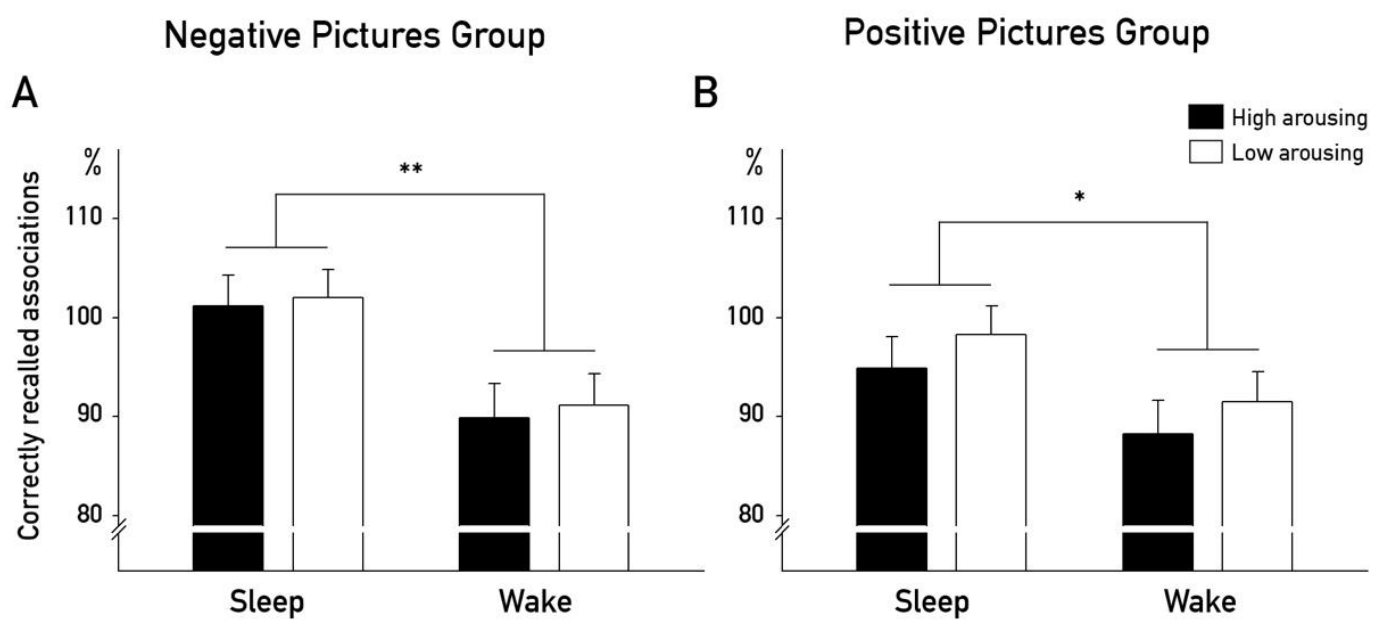

C

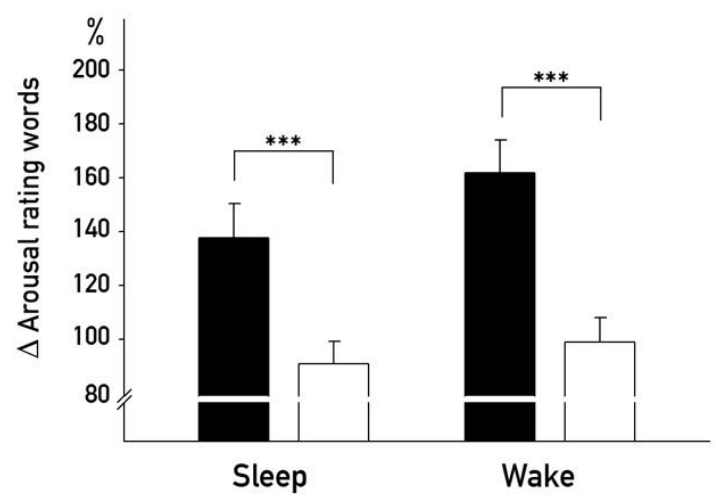

D

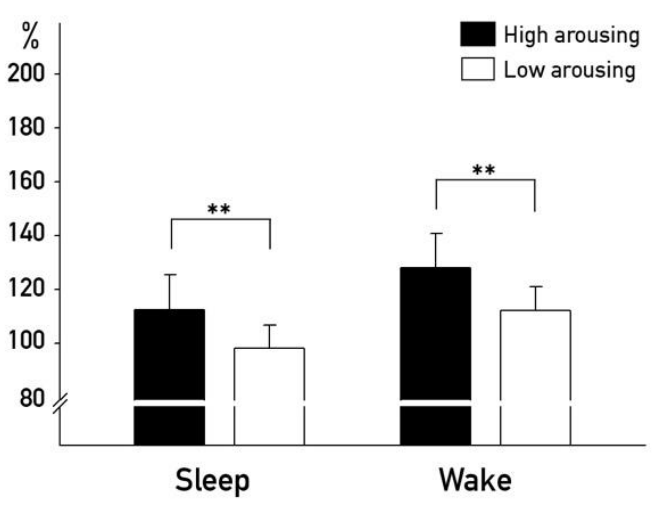

Behavioral results. A + B Changes in cued recall performance. After a retention interval filled with sleep, participants were significantly better in recalling word-picture associations as compared to participants who stayed awake after learning (main effect of sleep vs. wakefulness; $P<0.001$, eta ${ }^{2}=$ 0.14). However, the sleep benefit was not selective for associations with high emotional arousal, but similarly occurred for emotional pictures (high arousing, black bars) and neutral pictures (low arousing, white bars). In addition, the general sleep benefit was not affect by emotional valence (positive vs. negative pictures) and was similarly visible in both picture groups. Changes in cued recall performance are indicated as percentage of recalled associations with performance before the retention interval set to $100 \%$. C + D Changes in arousal ratings of neutral words. Words that were associated with high arousing pictures during the learning phase were rated overall as more arousing as compared to words with low arousing picture associations after the 12-hr retention interval. No main effect or interaction with sleep vs. wakefulness was observed. Changes in arousal ratings are indicated as percentage of ratings giving at the end of the experimental procedure, with arousal rated before the learning phase set to $100 \%$. Values are mean \pm SEM. ${ }^{*} P P<0.05, * * P<0.01,{ }^{*} * * P<0.001$. 
Table 1

\begin{tabular}{crcc} 
& \multicolumn{1}{c}{$\boldsymbol{N}$} & Age & m/f \\
\hline \multicolumn{2}{c}{ Negative Pictures Group } & & \\
Sleep & 20 & $22.5 \pm 0.5$ & $15 / 5$ \\
$\underline{\text { Wake }}$ & 16 & $21.8 \pm 0.5$ & $11 / 5$ \\
\hline Positive Pictures Group & & \\
$\underline{\text { Sleep }}$ & 19 & $22.0 \pm 0.9$ & $17 / 2$ \\
Wake & 17 & $21.6 \pm 0.3$ & $15 / 2$ \\
\hline
\end{tabular}

Demographic data of the four experimental groups. 
Table 2

\begin{tabular}{|c|c|c|c|c|c|}
\hline & & Arousing & Non-arousing & $t$ & $P$ \\
\hline \multicolumn{6}{|c|}{ All participants } \\
\hline Cued recall & Learning & $31.28 \pm 1.10$ & $28.90 \pm 1.12$ & 4.65 & $<0.001$ \\
\hline Word rating & Baseline & $2.68 \pm 0.12$ & $2.71 \pm 0.11$ & -0.57 & 0.57 \\
\hline Picture rating & Baseline & $4.52 \pm 0.12$ & $2.45 \pm 0.10$ & 13.60 & $<0.001$ \\
\hline \multicolumn{6}{|c|}{ Negative Pictures Group } \\
\hline Cued recall & Learning & $29.21 \pm 1.56$ & $27.86 \pm 1.59$ & 2.06 & 0.047 \\
\hline Word rating & Baseline & $2.97 \pm 0.17$ & $3.0 \pm 0.16$ & -0.36 & 0.72 \\
\hline Picture rating & Baseline & $5.01 \pm 0.17$ & $2.38 \pm 0.14$ & 15.69 & $<0.001$ \\
\hline \multicolumn{6}{|c|}{ Positive Pictures Group } \\
\hline Cued recall & Learning & $33.35 \pm 1.56$ & $29.94 \pm 1.58$ & 4.50 & $<0.001$ \\
\hline Word rating & Baseline & $2.38 \pm 0.16$ & $2.42 \pm 0.16$ & -0.44 & 0.66 \\
\hline Picture rating & Baseline & $4.02 \pm 0.17$ & $2.51 \pm 0.14$ & 6.87 & $<0.001$ \\
\hline
\end{tabular}

Numbers indicate absolute values of correctly recalled pictures after presentation of the word (of total 50 ) or arousal ratings (on a 7-point Likert-scale) prior to the retention interval. Data are means $\pm \mathrm{SEM}$. 
Table 3

\begin{tabular}{|c|c|c|c|c|c|}
\hline \multirow{2}{*}{\multicolumn{2}{|c|}{ All participants }} & \multirow{2}{*}{$\begin{array}{c}\text { Sleep } \\
N=39\end{array}$} & \multirow{2}{*}{$\begin{array}{l}\text { Wake } \\
N=33\end{array}$} & \multirow[t]{2}{*}{$t$} & \multirow[t]{2}{*}{$P$} \\
\hline & & & & & \\
\hline Cued recall & All pictures & $99.07 \pm 1.80$ & $90.19 \pm 1.96$ & 3.51 & 0.001 \\
\hline \multirow{5}{*}{ Word rating } & Arousing & $98.01 \pm 2.23$ & $89.06 \pm 2.42$ & 2.75 & 0.008 \\
\hline & Non-arousing & $100.13 \pm 2.03$ & $91.32 \pm 2.20$ & 2.99 & 0.004 \\
\hline & All pictures & $109.76 \pm 6.73$ & $125.13 \pm 7.32$ & -1.46 & 0.15 \\
\hline & Arousing & $125.01 \pm 9.05$ & $144.80 \pm 9.84$ & -1.39 & 0.17 \\
\hline & Non-arousing & $94.50 \pm 5.88$ & $105.46 \pm 6.31$ & -1.30 & 0.20 \\
\hline \multicolumn{2}{|c|}{ Negative Pictures Group } & $N=20$ & $N=16$ & & \\
\hline \multirow[t]{3}{*}{ Cued recall } & All pictures & $101.58 \pm 2.51$ & $90.51 \pm 2.81$ & 2.63 & 0.01 \\
\hline & Arousing & $101.15 \pm 3.11$ & $89.85 \pm 3.48$ & 2.01 & 0.05 \\
\hline & Non-arousing & $102.00 \pm 2.83$ & $91.16 \pm 3.16$ & 2.64 & 0.01 \\
\hline \multirow[t]{3}{*}{ Word rating } & All pictures & $114.21 \pm 9.39$ & $130.31 \pm 10.51$ & -1.15 & 0.26 \\
\hline & Arousing & $137.56 \pm 12.63$ & $161.74 \pm 12.13$ & -1.21 & 0.27 \\
\hline & Non-arousing & $90.87 \pm 8.21$ & $98.86 \pm 9.17$ & -0.92 & 0.36 \\
\hline \multicolumn{2}{|c|}{ Positive Pictures Group } & $N=19$ & $N=17$ & & \\
\hline \multirow[t]{3}{*}{ Cued recall } & All pictures & $96.56 \pm 2.58$ & $89.88 \pm 2.72$ & 2.28 & 0.03 \\
\hline & Arousing & $94.86 \pm 3.19$ & $88.27 \pm 3.37$ & 1.94 & 0.06 \\
\hline & Non-arousing & $98.26 \pm 2.90$ & $91.48 \pm 3.07$ & 1.56 & 0.13 \\
\hline \multirow[t]{3}{*}{ Word rating } & All pictures & $105.29 \pm 9.64$ & $119.96 \pm 10.19$ & -0.92 & 0.35 \\
\hline & Arousing & $112.46 \pm 12.96$ & $127.87 \pm 12.70$ & -0.87 & 0.39 \\
\hline & Non-arousing & $98.13 \pm 8.42$ & $112.05 \pm 8.90$ & -0.93 & 0.36 \\
\hline
\end{tabular}

Numbers indicate change of correctly recalled associations or change in arousal ratings for words. Change is in percentage (\%) and refers to the relative difference from prior to after the retention interval, while the first recall / rating is set to $100 \%$. Therefore a value $<100 \%$ indicates a decrease and a value $>100 \%$ an increase across the retention interval. Data are means \pm SEM. 